\title{
Supporting Information \\ Wearable Bracelet Monitoring the Solar \\ Ultraviolet Radiation for Skin Health Based on Hybrid IPN Hydrogels
}

Neng Hu, ${ }^{1}$ Li Lin, ${ }^{1}$ Jun Tan, ${ }^{2, *}$ Weijia Wang,,${ }^{3, *}$ Lin Lei, ${ }^{3}$ Huiqing Fan, ${ }^{3}$ Jiping Wang, ${ }^{4}$ Peter Müller-Buschbaum ${ }^{5,6}$ and Qi Zhong ${ }^{1,5, *}$

${ }^{1}$ Key Laboratory of Advanced Textile Materials \& Manufacturing Technology, Ministry of Education, Zhejiang Sci-Tech University, 310018 Hangzhou, China

${ }^{2}$ College of Biological, Chemical Science and Engineering, Jiaxing University, 314001 Jiaxing, China

${ }^{3}$ State Key Laboratory of Solidification Processing, School of Materials Science and Engineering, Northwestern Polytechnical University, 710072 Xi'an, China

${ }^{4}$ Shanghai University of Engineering Science, 333 Long Teng Road, 201620 Shanghai, China

${ }^{5}$ Technische Universität München, Physik-Department, Lehrstuhl für Funktionelle Materialien, James-Franck-Str. 1, 85748 Garching, Germany ${ }^{6}$ Heinz Maier-Leibnitz Zentrum (MLZ), Technische Universität München, Lichtenbergstr. 1, 85748 Garching, Germany

*Corresponding author.

qi.zhong@zstu.edu.cn Phone +86 57186843436 Fax +86 57186843436 


\section{weijia.wang@nwpu.edu.cn}

\section{Scanning electron microscopy (SEM)}

The scanning electron microscope (JSM-5610LV, JEOL, Japan) was applied to observe the morphology of hybrid IPN hydrogels. The accelerating voltage applied in the measurements was $10 \mathrm{kV}$. Before the measurements, the hybrid IPN hydrogels were sputter-coated with platinum by an auto fine coater (JFC-1600, JEOL, Japan).

\section{Cryo-scanning electron microscopy}

Cryo-scanning electron microscopy (FEI Quanta 450, Thermo Fisher, US) was applied to observe the cross-section images from alginate- $\mathrm{Ca}^{2+} / \mathrm{g}-\mathrm{C}_{3} \mathrm{~N}_{4}$ hydrogels, $\mathrm{P}$ (NIPAMco-OEGMA $\left.{ }_{300}\right) / \mathrm{g}-\mathrm{C}_{3} \mathrm{~N}_{4}$ hydrogels and hybrid alginate- $\mathrm{Ca}^{2+} / \mathrm{P}(\mathrm{NIPAM}-\mathrm{co}-$ $\left.\mathrm{OEGMA}_{300}\right) / \mathrm{g}-\mathrm{C}_{3} \mathrm{~N}_{4}$ IPN hydrogels. The accelerating voltage applied in the measurements was $5 \mathrm{kV}$.

\section{Transmission electron microscopy (TEM)}

Transmission electron microscopy (JEM-2100, JEOL, Japan) was applied to probe the distribution of $\mathrm{g}-\mathrm{C}_{3} \mathrm{~N}_{4}$ in the hybrid IPN hydrogels coinitiated by APS/TEMED and $\mathrm{g}$ $\mathrm{C}_{3} \mathrm{~N}_{4} /$ triethylamine, respectively. The accelerating voltage applied in the measurements was $150 \mathrm{kV}$. Because the hybrid IPN hydrogels are bulk materials, the embedded sectioning technique (UC7, Leica, Germany) was applied to prepare the samples for TEM measurements. 
a)

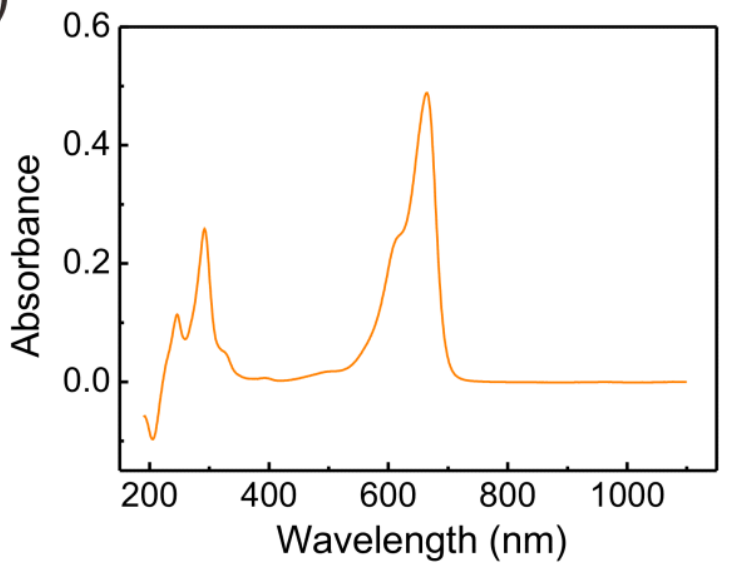

b)



C)

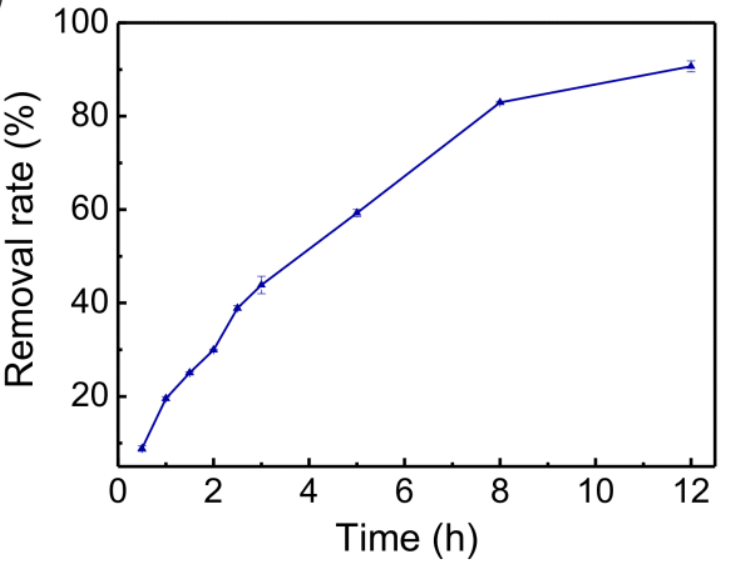

Figure S1. (a) Full UV-Vis absorption spectrum of the MB solution $\left(10 \mathrm{mg} \mathrm{mL}^{-1}\right)$. (b) UV-Vis absorption spectrum of MB solution after exposure to light radiation for different times as indicated by the colors. (c) The MB removal rates of hybrid alginate- $\mathrm{Ca}^{2+} / \mathrm{P}$ (NIPAM-co$\left.\mathrm{OEGMA}_{300}\right) / \mathrm{g}-\mathrm{C}_{3} \mathrm{~N}_{4}$ IPN hydrogels as a function of radiation time. 


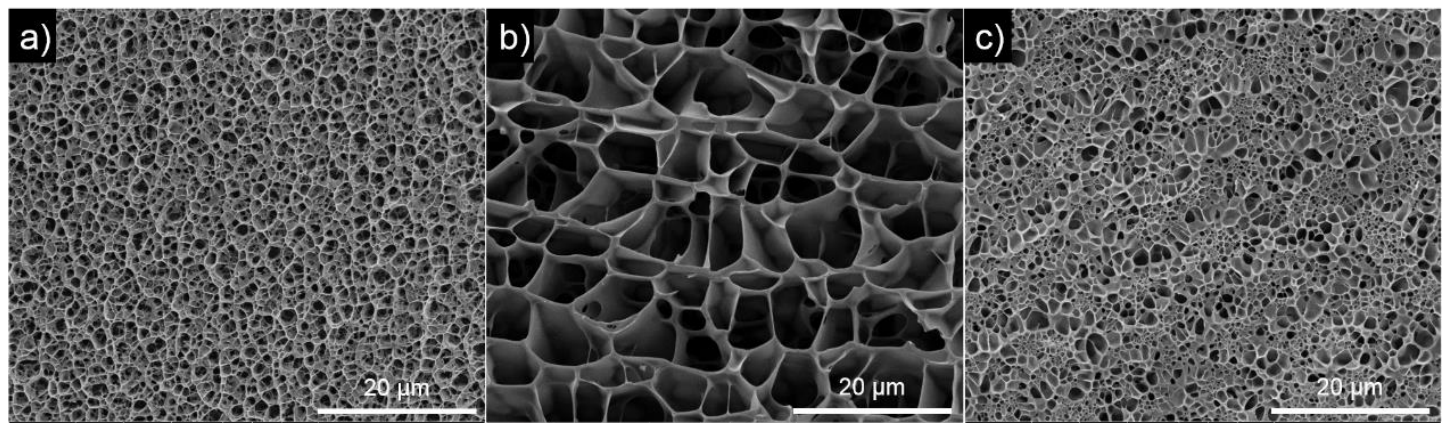

Figure S2. Cryo-SEM images of cross-sections from (a) alginate- $\mathrm{Ca}^{2+} / \mathrm{g}-\mathrm{C}_{3} \mathrm{~N}_{4}$ hydrogels, (b) $\mathrm{P}\left(\mathrm{NIPAM}-\mathrm{co}-\mathrm{OEGMA} \mathrm{A}_{300}\right) / \mathrm{g}-\mathrm{C}_{3} \mathrm{~N}_{4}$ hydrogels and (c) hybrid alginate-Ca ${ }^{2+} / \mathrm{P}(\mathrm{NIPAM}-\mathrm{co}-$ $\left.\mathrm{OEGMA}_{300}\right) / \mathrm{g}-\mathrm{C}_{3} \mathrm{~N}_{4}$ IPN hydrogels.
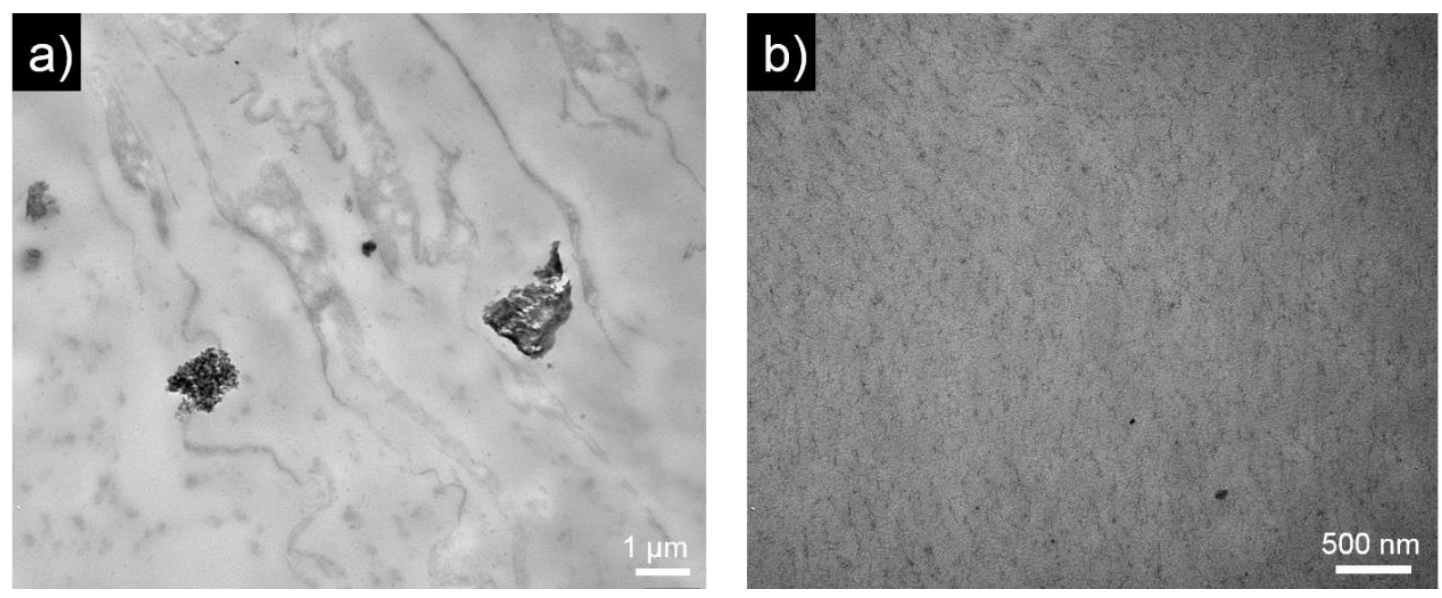

Figure S3. TEM images of hybrid alginate- $\mathrm{Ca}^{2+} / \mathrm{P}\left(\mathrm{NIPAM}-\mathrm{co}-\mathrm{OEGMA} \mathrm{A}_{300}\right) / \mathrm{g}-\mathrm{C}_{3} \mathrm{~N}_{4}$ IPN hydrogels coinitiated by (a) APS/TEMED and (b) g- $\mathrm{C}_{3} \mathrm{~N}_{4} /$ triethylamine. 
a)

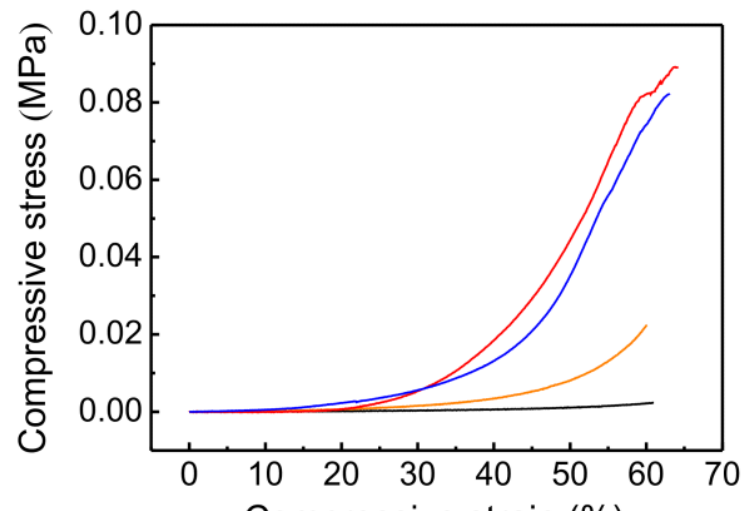

b)

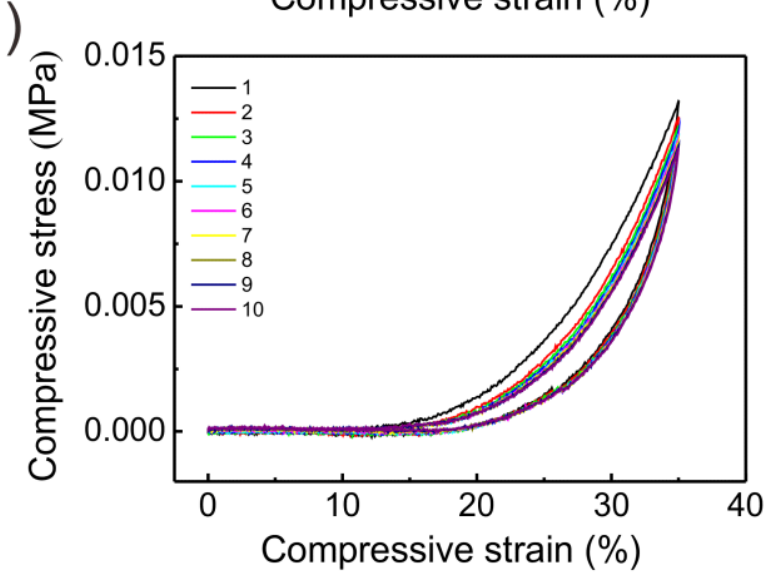

Figure S4. (a) Compressive stress-strain curves of $\mathrm{P}\left(\mathrm{NIPAM}-\mathrm{co}-\mathrm{OEGMA} \mathrm{A}_{300}\right) / \mathrm{g}-\mathrm{C}_{3} \mathrm{~N}_{4}$ hydrogels (black), alginate- $\mathrm{Ca}^{2+} / \mathrm{g}-\mathrm{C}_{3} \mathrm{~N}_{4}$ hydrogels (orange), hybrid alginate-Ca ${ }^{2+} / \mathrm{P}(\mathrm{NIPAM}-$ co-OEGMA $\left.{ }_{300}\right) / \mathrm{g}_{-} \mathrm{C}_{3} \mathrm{~N}_{4}$ IPN hydrogels coinitiated by APS/TEMED (blue) and g$\mathrm{C}_{3} \mathrm{~N}_{4} /$ triethylamine (red), respectively. (b) 10 cycles of compression curves of the hybrid alginate- $\mathrm{Ca}^{2+} / \mathrm{P}\left(\mathrm{NIPAM}-\mathrm{co}-\mathrm{OEGMA}{ }_{300}\right) / \mathrm{g}^{-} \mathrm{C}_{3} \mathrm{~N}_{4}$ IPN hydrogels coinitiated by $\mathrm{g}$ $\mathrm{C}_{3} \mathrm{~N}_{4} /$ triethylamine. 